\title{
Quality Management System: Analisis Raport Mutu Usaha Kesehatan Sekolah (UKS)
}

\author{
Sapto Irawan, Danu Prasetyo \\ sapto.irawan@uksw.edu, danupancasila@yahoo.com \\ FKIP Universitas Kristen Satya Wacana, SMK PGRI 1 Salatiga
}

Quality Management System: Quality Report Analysis Of The School Health Efforts

\begin{abstract}
This quality report analysis was conducted to see the quality achievement of SMK PGRI 1 Salatiga in one year for School Health Efforts (UKS) in 2018. This research describes descriptively both qualitatively and quantitatively the results of the quality report card achievement. It was shown that the achievement score in the School Health Business Report Card (UKS) was 6.6 with the category of UKS 4. Referring to the results of the analysis of the description above, it showed that the achievement report had obtained the four-star category. Validation of the achievement of the School Health Effort report card (UKS) is needed to show the real condition of the school. The achievement of the four-star category is strongly influenced by two important factors in its implementation, namely: 1) the awareness of all school members to realize a healthy lifestyle; 2) the facilities and infrastructure support in realizing healthy living behavior.
\end{abstract}

Keywords: Quality Management System, Quality Report, UKS

\begin{tabular}{lcc}
\hline & Article Info \\
Received date: 17 Desember 2019 & Revised date: 14 April $2020 \quad$ Accepted date: 12 Mei 2020
\end{tabular}

\section{PENDAHULUAN}

Mutu merupakan sebuah keseluruhan ciri atau karakteristik produk atau jasa dalam tujuannya untuk memenuhi kebutuhan dan harapan pelanggan. Ketercapaian mutu tidak terlepas dari adanya faktor-faktor pendukung baik secara internal maupun eksternal. Dalam konteks dunia pendidikan, mutu pendidikan dimaknai sebagai sebuah hasil capaian yang dilakukan oleh satuan pendidikan. Sedangkan Menurut Undang-Undang Nomor 20 Tahun 2003 Tentang Sistem Pendidikan Nasional, Pendidikan adalah usaha sadar dan terencana untuk mewujudkan suasana belajar dan proses pembelajaran agar peserta didik secara aktif mengembangkan potensi dirinya untuk memiliki kekuatan spiritual keagamaan, pengendalian diri, kepribadian, kecerdasan, akhlak mulia, serta keterampilan yang diperlukan dirinya, masyarakat, bangsa dan negara. Berdasarkan pemahaman definisi tersebut, konsep mutu pendidikan tidak terlepas dari sebuah proses pembelajaran yang dilakukan oleh peserta didik. Seyogyanya terdapat unsur-unsur yang terkandung dalam wujud mutu pendidikan pada satuan pendidikan, diantaranya kekuatan spiritual keagamaan, pengendalian diri, kepribadian, kecerdasan, akhlak mulia, serta keterampilan.

Mutu pendidikan diperlukan untuk menjaga eksistensi dan keberadaan sebuah satuan pendidikan, hal tersebut dilakukan dengan mempertimbangkan berbagai aspek yang dimiliki oleh sekolah. Standar Nasional Pendidikan merupakan indikator yang menjadi sebuah tolak ukur dalam melihat mutu pendidikan sekolah, hal tersebut telah tertuang dalam Peraturan Pemerintah Nomor 13 Tahun 2015 Tentang Standar Nasional Pendidikan. Terdapat delapan (8) standar yang menjadi indikator mutu sekolah, yang mencakup : 1). Standar Kompetensi Lulusan; 2). Standar Isi; 3). Standar Proses; 4). Standar Penilaian; 5). Standar Pendidik dan Tenaga Kependidikan; 6). Standar Sarana dan Prasarana; 7). Standar Pengelolaan dan 8). Standar Pembiayaan. Kedelapan standar pendidikan tersebut nampaknya menjadi salah satu tolak ukur bagi sekolah guna mengetahui seberapa jauh kualitas mutu yang dimiliki oleh sebuah satuan pendidikan. Selain merujuk pada kedelapan standar pendidikan, indikator pencapaian mutu pendidikan juga dapat dilihat melalui nilai-nilai karakter, kegiatan kesehatan sampai dengan kegiatan literasi sekolah. 
Ketercapaian mutu pendidikan sekolah baik mencakup penjaminan mutu pendidikan, pendidikan karakter, kegiatan kesehatan sekolah, sampai dengan literasi sekolah dapat dilihat melalui hasil raport mutu sekolah. Raport mutu sekolah merupakan hasil capaian yang diperoleh sekolah terkait dengan upaya peningkatan mutu yang telah dilakukan sekolah tersebut. Hasil raport mutu yang digunakan untuk melihat peningkatan mutu pendidikan yang dilakukan sekolah mencakup raport mutu: Usaha Kesehatan Sekolah (UKS), Gerakan Literasi Sekolah (GLS) dan Penguatan Pendidikan Karakter (PPK). Sekolah Menengah Kejuruan (SMK) PGRI 1 Salatiga merupakan satuan pendidikan yang berorientasi pada pendidikan menengah kejuruan. Ketercapaian mutu pendidikan di SMK PGRI 1 Salatiga, tidak terlepas dari delapan (8) standar nasional pendidikan melalui penjaminan mutu pendidikan, penguatan pendidikan karakter, gerakan literasi sekolah dan usaha kesehatan sekolah. Secara umum bahwa keempat indikator capaian mutu tersebut, dapat dilihat melalui hasil raport mutu yang diperoleh melalui hasil evaluasi diri sekolah. Fakta dilapangan dan kondisi riil disekolah terkadang berbeda dengan hasil raport mutu sekolah. Hal ini menunjukkan adanya kesenjangan antara raport mutu sekolah dengan kondisi riil dan fakta yang ada disekolah, salah satunya raport mutu sekolah tentang Usaha Kesehatan Sekolah (UKS) yang ada di SMK PGRI 1 Salatiga. Guna mengetahui sejauh mana ketercapaian mutu di SMK PGRI 1 Salatiga, maka dilakukan kajian terhadap Analisis Raport Mutu Terhadap Sistem Penjaminan Mutu di SMK PGRI 1 Salatiga khususnya pada Raport Mutu Usaha Kesehatan Sekolah (UKS).

Berdasarkan latar belakang tersebut, bagaimana analisis capaian raport mutu pendidikan di SMK PGRI 1 Salatiga dilihat dari raport mutu Usaha Kesehatan Sekolah? Tujuan tulisan ini yaitu untuk mengetahui gambaran analisis Raport Mutu Usaha Kesehatan Sekolah (UKS) di SMK PGRI 1 Salatiga. Hasil analisis raport mutu ini diharapkan dapat bermanfaat bagi pihak-pihak terkait dalam rangka untuk menentukan rencana kerja dan tindak lanjut yang diperlukan untuk perbaikan berkelanjutan.

\section{KAJIAN PUSTAKA}

\section{Quality Management System}

Konsep quality management system (TQM) juga dipahami sebagai sebuah manajemen mutu dalam hal peningkatan pendidikan, produk maupun sumber daya manusia. Pemahaman tentang manajemen mutu memiliki berbagai perspektif dari pendapat ahli. Sistem manajemen mutu merupakan sekumpulan prosedur terdokumentasi dan praktek-praktek standar untuk menajemen sistem yang menjamin kesesuaian dari suatu proses dan produk (barang/jasa) terhadap kebutuhan atau persyaratan tertentu, kebutuhan atau persyaratan itu ditentukan atau dispesifikasikan oleh pelanggan atau organisasi (Gasperz dalam Fitri, 2011: 424).

Pengertian sistem manajemen mutu tersebut, berupaya memberikan pemahaman bahwa mutu sebagai sebuah prosedur yang terdokumentasi. Manajemen mutu juga dipahami sebagai sistem manajemen yang mengangkat kualitas sebagai strategi usaha dan berorientasi pada kepuasan pelanggan dengan melibatkan seluruh anggota organisasi (Saril, 2019: 965). Konsep TQM pada sumber lain dijelaskan bahwa suatu pendekatan dalam usaha memaksimalkan daya saing melalui perbaikan terus-menerus atas jasa, manusia, produk dan lingkungan. Di dalam TQM terdapat serangkaian usaha untuk memaksimalkan semua fungsi dari pada organisasi dalam falsafah holistis yang dibangun berdasarkan konsep mutu, kerja tim, efektivitas, dan prestasi serta kepuasan pelanggan (Zahroh, A., 2015: 81).

Upaya untuk mewujudkan quality management mutu dapat dipengaruhi oleh beberapa faktor penting yang mampu untuk mewujudkan peningkatan manajemen mutu (Supriyanto, 2011: 27) antara lain yaitu: Perumusan tujuan peningkatan mutu, Penerapan prinsip-prinsip mutu, Komponen pendukung implementasi TQM. Ketiga faktor tersebut memberikan gambaran bahwa dalam mewujudkan peningkatan terhadap manajemen mutu, minimal memerlukan sebuah tujuan, prinsip serta dukungan agar mampu mencapai quality management. Sinergitas dalam mewujudkan manajemen mutu, seyogyanya tidak hanya terbatas pada ketiga komponen tersebut, namun demikian upaya yang berkesinambungan harus terus dilakukan guna mencapai stabilitas dan konsistensi dalam meningkatan dan mempertahankan mutu. 


\section{Konsep Mutu}

Mutu merupakan sebuah cara yang menentukan sebuah produk atau jasa yang dihasilkan sudah sesuai dengan standar yang telah ditetapkan. Sedangkan konsep mutu yang dimaskud dalam pendidikan yakni meliputi komponen siswa, guru, dana, sarana dan prasarana, proses pembelajaran dan komponen masyarakat. Menurut (Sallis, 2008: 56) "mutu merupakan sesuatu yang memuaskan dan melampaui keinginan dann kebutuhan pelanggan". Konsep mutu juga tidak bisa dipisahkan dengan dana atau biaya pendidikan, seperti hasil penelitian Togatorop M. (2017: 238) yang menunjukkan bahwa terdapat pengaruh langsung biaya pendidikan terhadap mutu pendidikan dengan nilai koefisien korelasi sebesar 0,491 dan nilai koefisien jalur sebesar 0,367 , yang berarti bahwa biaya pendidikan berpengaruh positif terhadap mutu sekolah.

Senada dengan konsep mutu pada bagian sebelumnya, Deming dalam (Usman, 2013: 540)" mengatakan bahwa mutu merupakan kesesuaian produk dengan kebutuhan pasar". Sehingga definisi mutu dalam hal ini lebih terfokus kepada kesesuaian terhadap kebutuhan pasar. Selain itu menurut Burnham dalam (Usman, 2013: 540) "mutu merupakan ukuran relatif suatu sasaran produk atau jasa sesuai dengan standar mutu desain". Berdasarkan pendapat bebrapa ahli diatas tentang pengertian mutu, maka mutu (Sallis, 2008: 56); Deming (dalam Usmam, 2013: 540); Burnham (dalam Usman, 2013: 540) merupakan suatu kesesuaian suatu produk atau jasa yang dihasilkan sesuai dengan standar dan dapat memuaskan kebutuhan pelanggan.

Merujuk pada pengertian tersebut, konteks mutu dalam pendidikan dipahami bahwa mutu merupakan pelayanan jasa dari pemberi jasa kepada yang menggunakan jasanya atau dari sekolah kepada masyarakat. Sehingga mutu dalam konteks pendidikan ini lebih berorientasi kepada pelayanan jasa yang diberikan kepada pelanggan. Manajemen mutu pendidikan didefinisikan sebagai suatu penedekatan dalam usaha memaksimalkan daya saing melaui perbaikan terus-menerus atas jasa, manusia, produk dan lingkungan (Tjiptono \& Anastasia dalam Usman, 2013: 560). Definisi tersebut memberikan penjelasan bahwa guna meningkatkan mutu pendidikan diperlukan perbaikan secara berkelanjutan, sehingga memperoleh hasil yang maksimal. Dalam meningkatkan mutu pendidikan, terdapat beberapa faktor yang mempengaruhinya yaitu:

1. Komitmen pimpinan puncak (Top Management)

Manajemen mutu terpadu tidak akan tercapai tanpa dukungan dari manjemen puncak. Spanbauer dalam Sallis (2008: 56) "Jika kepala sekolah saja sudah tidak peduli terhadap kepemimpinan dan komitmen mutu ini, maka sekolah terancam akan gagal menerapkannya. ketika kondisi sekolah sudah sedemikian, maka manajer menengah juga tidak dapat menentukan kesuksesan. oleh karena itu pemimpin sekolah harus menunjukkan komitmen yang kuat dan selalu memotivasi wakil kepala sekolah dan supervisor lainnya agar selalu berupaya keras dan serius."

2. Partisipasi Konsumen Internal

Konsumen internal dalam suatu sekolah adalah guru-guru, tenaga administrasi, dan siswa. Keterlibatan konsumen internal yaitu dalam memberikan informasi mengenai pembelajaran dan sistem pembelajaran akan mempermudah manajemen atau team penjamin mutu dalam membuat keputusan mengenai perencanaan, pengorganisasian untuk menerapkan Manajemen Mutu Terpadu (MMT) yang berkelanjutan dalam meningkatkan produktivitas pendidikan.

3. Hubungan dengan Pemasok

Hubungan dengan pemasok dalam konteks dunia pendidikan di tingkat SMK adalah SMP Negeri maupun Swasta. Kerja sama dengan pemasok dalam hal ini dengan menawarkan peluang beasiswa prestasi dan menawarkan produk-produk sekolah yang dimiliki.

4. Desain Kurikulum

Desain kurikulum memberikan kontribusi positif untuk meningkatkan produktivitas pendidikan, karena ada hubungan yang erat antara mutu produk dengan kepuasan pelanggan dan manfaat pendidikan. Desain kurikulum merupakan faktor penting dalam memberikan dukungan untuk tercapainya penerapan manajemen mutu terpadu, karena kurikulum meliputi input (guru, mata pelajaran), proses (sistem pembelajaran, sarana dalam proses pembelajaran) sehingga menghasilkan lulusan yang mempunyai kompetensi yang sesuai dengan perkembangan dunia kerja dan dunia pendidikan.

5. Sarana dan Prasarana

Berdasarkan Permendiknas No 24 Tahun 2007 Tentang Standar Sarana dan Prasarana SMA/MA, meliputi satuan pendidikan, lahan, bangunan gedung, kelengkapan sarana dan prasarana (ruang 
kelas, lab, ruang pustaka, toilet, ruang kepala sekolah, ruang tata usaha, ruang konseling, tempat ibadah). Sarana dan prasaran merupakan salah satu komponen utama dalam mendukung terlaksananya kegiatan pembelajaran di sekolah.

Berdasarkan paparan tersebut, sedikitnya lima faktor yang mempengaruhi peningkatan mutu pendidikan yaitu: Komitmen pimpinan puncak (Top Management), Partisipasi Konsumen Internal, Hubungan dengan Pemasok, Desain Kurikulum, dan Sarana dan Prasarana. Kelima faktor tersebut, akan saling terkait satu dengan yang lainnya dalam implementasi yang sesungguhnya dilapangan. Oleh kerena itu perlu memperhatikan setiap faktor tersebut untuk dapat meningkatkan mutu pendidikan secara umum disekolah.

\section{Raport Mutu Sekolah}

Sistem Penjaminan Mutu Pendidikan Dasar dan Menengah adalah suatu kesatuan unsur yang terdiri atas organisasi, kebijakan, dan proses terpadu yang mengatur segala kegiatan untuk meningkatkan mutu Pendidikan Dasar dan Menengah secara sistematis, terencana dan berkelanjutan. Tujuan Sistem penjaminan mutu pendidikan dasar dan menengah bertujuan menjamin pemenuhan standar pada satuan pendidikan dasar dan menengah secara sistemik, holistik, dan berkelanjutan, sehingga tumbuh dan berkembang budaya mutu pada satuan pendidikan secara mandiri. Fungsi Sistem penjaminan mutu pendidikan berfungsi sebagai pengendali penyelenggaraan pendidikan oleh satuan pendidikan untuk mewujudkan pendidikan yang bermutu.

Rapor mutu dari hasil Pemetaan Mutu Pendidikan (PMP) membantu untuk mengidentifikasi masalah, penilaian program dan pencapaian sasaran. Sekolah dapat mengidentifikasikan kelebihan serta kekurangannya sendiri dan merencanakan pengembangan kedepan. Memperkuat budaya evaluasi kelembagaan dan analisis-diri. Mendorong sekolah untuk meninjau kembali kebijakan yang telah usang. Memberi informasi tentang status sekolah dibandingkan dengan sekolah lain. Sekolah dapat memiliki data dasar yang akurat sebagai dasar untuk pengembangan dan peningkatan di masa mendatang. Munculnya hasil raport mutu pendidikan diawali dengan Sekolah melakukan kegiatan pemetaan mutu melalui Evaluasi Diri Sekolah (EDS) dan menyampaikan hasil evaluasi diri tersebut dalam bentuk data dan informasi sesuai dengan instrumen pemetaan mutu yang dikembangkan oleh Direktorat Jenderal Pendidikan Dasar dan Menengah dengan ketentuan yang ada (Nanang dan Rusman, 2019: 25).

Raport mutu pendidikan juga dimaknai sebagai upaya untuk mengukur peningkatan mutu yang dituangkan dalam Rencana Strategis Pembangunan Pendidikan dan memfasilitasi pemenuhan mutu di seluruh satuan pendidikan (Kemendikbud, 2019: 4). Merujuk pada uraian diatas, dapat dipahami adalah raport mutu pendidikan lebih dimaknai sebagai hasil dari capaian program yang direncanakan oleh satuan pendidikan. Pencapaian hasil raport mutu sekolah lebih mengarah pada hasil instrument Evaluasi Diri Sekolah (EDS) yang dibuat berdasarkan kondisi nyata yang terdapat pada satuan pendidikan.

\section{Sekolah Menengah Kejuruan}

Instruksi Presiden Nomor 9 Tahun 2019 Tentang Revitalisasi Sekolah Menengah Kejuruan merupakan upaya yang dilakukan oleh pemerintah untuk meningkatkan mutu pendidikan khususnya pada Sekolah Menengah Kejuruan. Lebuh lanjut bahwa Pendidikan Sekolah Menengah Kejuruan bertujuan untuk meningkatkan kecerdasan pengetahuan, kepribadian, ahlaq mulia, serta ketrampilan untuk hidup mandiri dan mengikuti pendidikan lebih lanjut dengan kejuruannya. Menurut Hamalik (2001: 24) pendidikan menengah kejuruan merupakan suatu bentuk pengembangan bakat, pendidikan dasar keterampilan dan kebiasaan-kebiasaan yang mengarah pada dunia kerja yang dipandang sebagai latihan keterampilan. Lebih lanjut untuk mencapai tujuan tersebut, diperlukan berbagai upaya baik oleh pemerintah maupun masyarakat. Terdapat lima (5) tujuan dengan diterbitkannya Instruksi Presiden Nomor 9 Tahun 2019 Tentang Revitalisasi Sekolah Menengah Kejuruan oleh Kemendikbud yakni: 1) Mewujudkan Link and Match dengan Dunia Usaha/Dunia Industri; 2) Mengubah paradigma dari push menjadi pull; 3) Mengubah pembelajaran dari supply driven menjadi demand driven: 4) Menyiapkan lulusan SMK yang adaptable terhadap perubahan dunia untuk menjadi lulusan yang dapat berkerja, melanjutkan dan berwirausaha; 5) Mengurangi/menghilangkan kesenjangan antara pendidikan kejuruan dengan kebutuhan Dunia Usaha dan Dunia Industri baik dari aspek teknologi, administratif maupun kompetensi. 
Merujuk dari tujuan revitalisasi SMK diatas, dapat dipahami bahwa SMK perlu menjalin kerja sama dengan Dunia Usaha/Dunia Industri agar mampu memberikan bekal dan gambaran bagi peserta didik dalam memasuki dunia kerja. Sebagai salah satu sekolah yang mencetak lulusan yang siap untuk memasuki dunia kerja, SMK harus memiliki Standar Kompetensi Lulusan yang siap untuk bersaing. Peraturan Menteri Pendidikan dan Kebudayaan Nomor 20 Tahun 2016 Tentang Standar Kompetensi Lulusan menjadi salah satu dasar bagi SMK dalam menghasilkan lulusan yang berdaya saing dan siap untuk memasuki dunia kerja. Menghasilkan lulusan yang memiliki daya saing dan kualitas menjadi tugas utama baik bagi pemerintah maupun masyarakat. Selain itu, faktor lain terhadap kondisi sumber daya manusia di Indonesia yang memiliki potensi mengalami penurunan. Peningkatan sumber daya manusia di Indonesia baik dari segi kualitas maupun kuantitas salah satunya melalui pendidikan menengah kejuruan.

\section{METODE PENELITIAN}

Analisis Raport Mutu Usaha Kesehatan Sekolah di SMK PGRI 1 Salatiga merupakan jenis penelitian deskriptif kualitatif. Penelitian kualitatif, berupaya untuk melihat fenoma atau mengumpulkan informasi-informasi yang bermakna secara lebih mendalam (Sugiyono, 2011: 20). Penelitian ini berupaya menganalisis tentang hasil raport mutu Usaha Kesehatan Sekolah di SMK PGRI 1 Salatiga dengan merujuk hasil raport mutu sekolah tahun 2018.

Teknik pengumpulan data dalam penelitian ini menggunakan wawancara, observasi, dan studi dokumentasi. Aspek dan Indikator pengumpulan data meliputi beberapa hal berikut seperti yang paparkan pada tabel 1 .

Tabel 1. Aspek dan Indikator Pengumpulan Data

\begin{tabular}{cllccc}
\hline No & \multicolumn{1}{c}{ Aspek } & \multicolumn{1}{c}{ Indikator } & Wawancara & Observasi & Dokumentasi \\
\hline \multirow{2}{*}{1} & Pendidikan & Sosialiasi hidup bersih & v & v & v \\
\cline { 3 - 6 } & Kesehatan & Trias UKS & & & v \\
\hline \multirow{2}{*}{2} & $\begin{array}{l}\text { Pelayanan } \\
\text { Kesehatan }\end{array}$ & Kerja sama eksternal & & & Layanan UKS \\
\cline { 3 - 6 } & Pembinaan & Fasilitas kesehatan & & & v \\
\cline { 3 - 6 } 3 & $\begin{array}{l}\text { Lingkungan } \\
\text { Sekolah Sehat }\end{array}$ & Perilaku hidup bersih & & $\mathrm{v}$ & \\
\cline { 3 - 6 } & & Perilaku hidup sehat & $\mathrm{v}$ & & \\
\hline
\end{tabular}

Kegiatan teknik analisis data dalam penelitian ini meliputi beberapa hal sebagai berikut: 1). Koleksi data, 2). Reduksi Data, 3). Display Data, 4). Verifikasi/ Kesimpulan data (Miles and Huberman dalam Sugiyono, 2013: 334). Setelah data terkumpul, dilakukan reduksi data terhadap data-data yang relevan dan mendukung. Penyajian data dan verifiaksi data dilakukan sebagai bagian akhir dalam analisis data penelitian ini dengan memvaliadasi data melalui observasi terhadap pengamatan langsung dilapangan.

\section{HASIL PENELITIAN DAN PEMBAHASAN}

\section{Raport Mutu Usaha Kesehatan Sekolah}

Raport mutu Usaha Kesehatan Sekolah (UKS) berupaya untuk mengukur sejauh mana capain yang diperoleh sekolah dalam menjaga dan meningkatkan kesehatan sekolah. Upaya tersebut seyogyanya tidak terlepas dari peran serta seluruh warga sekolah baik peserta didik, guru maupun komite sekolah. Secara umum bahwa pencapaian mutu tentang Usaha Kesehatan Sekolah (UKS) dalam dilihat melalui hasil raport mutu Usaha Kesehatan Sekolah (UKS). Namun demikian, dalam uraian ini berupaya dilakukan validasi terhadap hasil raport mutu Usaha Kesehatan Sekolah (UKS) Tahun 2018 dengan kondisi riel di SMK PGRI 1 Salatiga. Pendeskripsian tentang gambaran raport mutu Usaha Kesehatan Sekolah (UKS) dapat di lihat melalui radar Usaha Kesehatan Sekolah (UKS), mengenai alur perkembangan dari hasil raport mutu SMK PGRI 1 Salatiga. Adapun untuk memahami tentang grafik perkembangan Usaha Kesehatan Sekolah (UKS) dapat dilihat melalui radar UKS pada gambar 1 tentang radar Usaha Kesehatan Sekolah (UKS) sebagai berikut: 


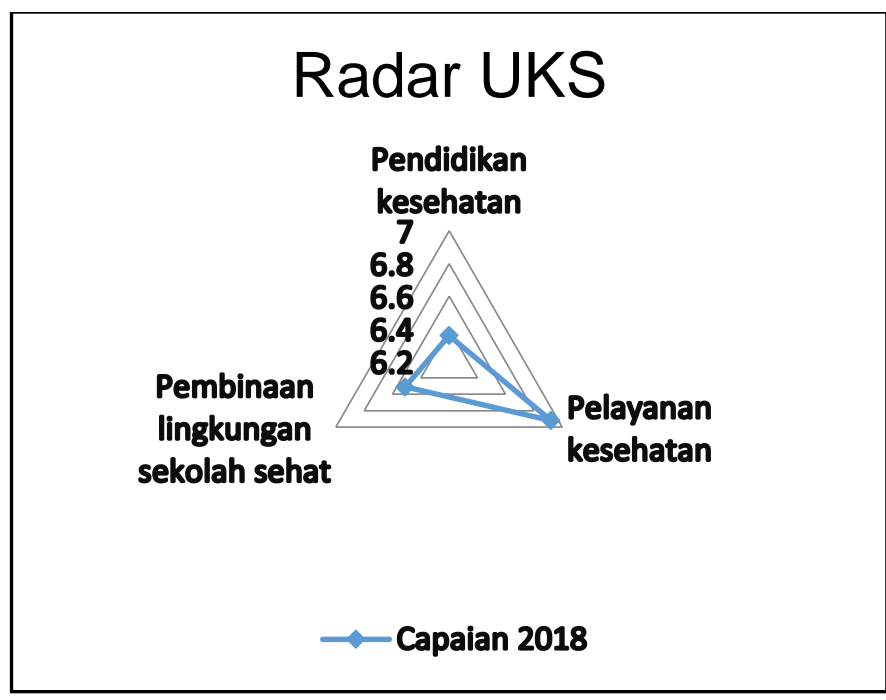

Gambar 1. Radar Usaha Kesehatan Sekolah (UKS) SMK PGRI 1 Salatiga Tahun 2018 (Sumber: Data Raport Mutu Dirjen Dikdasmen Kemendikbud 2018)

Berdasarkan pada gambar 1 tentang radar Usaha Kesehatan Sekolah (UKS) SMK PGRI 1 Salatiga, dapat dijelaskan bahwa hasil dari radar Usaha Kesehatan Sekolah (UKS) dilihat berdasarkan tiga (3) indikator capaian yaitu: 1). Pendidikan Kesehatan; 2). Pelayanan Kesehatan; 3). Pembinaan Lingkungan Sekolah Sehat. Pada indikator pertama yakni tentang pendidikan kesehatan memperoleh skor 6.4, dimana kategori skor dalam indikator pendidikan kesehatan termasuk dalam Usaha Kesehatan Sekolah kategori 4. Lebih lanjut dapat dijelaskan bahwa ketercapain sekolah dalam memperoleh kategori Usaha Kesehatan Sekolah 4, jika ditinjau dari hasil deskripsi raport mutu UKS tidak terlepas dari berbagai sub indikator yang mendukung hasil tersebut.

Pada indikator kedua tentang pelayanan kesehatan, memperoleh skor 6.8, dimana kategori skor dalam indikator pendidikan kesehatan termasuk dalam Usaha Kesehatan Sekolah kategori 4. Ketercapaian nilai skor pada indikator kedua tentang pelayanan kesehatan, merupakan kategori capain penilaian yang cukup tinggi. Berdasarkan hasil capain tersebut, lebih lanjut dapat jelaskan bahwa nampaknya terdapat berbagai sub indikator yang mengakibatkan tingginya capaian pada indikator tentang pelayanan kesehatan. Sedangkan pada indikator yang ketiga tentang Pembinaan Lingkungan Sekolah Sehat memperoleh skor 6.2, dimana berdasarkan pada skor indikator pendidikan kesehatan termasuk dalam Usaha Kesehatan Sekolah masuk kategori 4 yakni UKS 4.

Dalam pengkatagorian capaian raport mutu usaha kesehatan sekolah terdapat lima katagori capaian mutu seperti yang disajikan pada tabel 2 .

Tabel 2. Katagori Capaian Mutu UKS

\begin{tabular}{cccc}
\hline No & Interval skor & Simbol & Katagori Capaian \\
\hline 1 & $0-2.04$ & $*$ & UKS 1 \\
\hline 2 & $2.05-3.7$ & $* *$ & UKS 2 \\
\hline 3 & $3.71-5.06$ & $* * *$ & UKS 3 \\
\hline 4 & $5.07-6.66$ & $* * * *$ & UKS 4 \\
\hline 5 & $6.67-7$ & $* * * * *$ & UKS \\
\hline
\end{tabular}

Capaian raport mutu UKS di SMK PGRI 1 Salatiga rata-rata mendapatkan skor sebesar 6,5. Berdasarkan tabel 2 katagori capaian raport mutu, maka capaian tersebut termasuk dalam katagori UKS 4 dengan symbol bintang empat. Hal ini menunjukkan bahwa capaian tersebut berada pada posisi satu tingkat dibawah capaian tertinggi yaitu katagori UKS yang disimbolkan dengan bintang lima.

Uraian tentang hasil radar Usaha Kesehatan Sekolah tersebut, secara tidak langsung mampu memberikan gambaran sejauh mana ketercapaian mutu sekolah khususnya pada Usaha Kesehatan Sekolah di SMK PGRI 1 Salatiga. Ketiga indikator tersebut 1). Pendidikan Kesehatan; 2). Pelayanan Kesehatan; 3). Pembinaan Lingkungan Sekolah Sehat, atau disebut dengan Trias UKS masing-masing memiliki penilain yang berbeda. Namun demikian, dari ketiga indikator diatas, bahwa indikator tentang 
pelayanan kesehatan memiliki nilai yang cukup tinggi dibandingkan dengan ketiga indikator yang lainnya.

Analisis tentang hasil raport mutu, tidak hanya terbatas berdasarkan radar Usaha kesehatan sekolah saja. Namun demikian untuk lebih memahami secara mendalam perlu melakukan pembahasan berdasarkan pada capain raport mutu Usaha Kesehatan sekolah (UKS), yang secara detail memberikan data keterangan tentang indikator-indikator capaian raport mutu pendidikan. UKS sebagai salah satu wahana untuk meningkatkan ke- mampuan hidup sehat dan derajat kesehatan peserta didik serta menciptakan lingkungan yang sehat, maka program UKS mempunyai Trias UKS yang meliputi pendidikan kesehatan, pelayanan kesehatan dan pembinaan lingkungan kehidupan sekolah yang sehat (Effendy, 2008: 25).

Secara umum bahwa dalam menilai dan menganalisis raport mutu Usaha Kesehatan Sekolah (UKS) terdapat tiga (3) aspek yang menjadi indikator dalam penilaiannya yang digunakan oleh Direktorat Jenderal Pendidikan Dasar dan Menengah Kementerian Pendidikan dan Kebudayaan yakni 1). Pendidikan kesehatan; 2). Pelayanan kesehatan; 3). Pembinaan lingkungan sekolah sehat. Hasil raport mutu Usaha Kesehatan Sekolah (UKS) SMK PGRI 1 Salatiga dapat ditunjukkan melalui tabel 3 sebagai berikut:

Tabel 3. Capaian Raport Mutu Usaha Kesehatan Sekolah (UKS) Tahun 2018 SMK PGRI 1 Salatiga

\begin{tabular}{|c|c|c|c|}
\hline \multicolumn{2}{|c|}{ ASPEK/INDIKATOR } & \multicolumn{2}{|c|}{ CAPAIAN 2018} \\
\hline Nomor & Aspek/Indikator & Nilai & Kategori \\
\hline 01:00:00.000 & Pendidikan kesehatan & 6.36 & $\star \star \star \star$ \\
\hline 01:01:00.000 & Meningkatnya Perilaku Hidup Bersih dan Sehat & 7 & $\star \star \star \star \star$ \\
\hline 01:02:00.000 & $\begin{array}{l}\text { Meningkatnya pengetahuan sikap dan perilaku peserta didik tentang hidup } \\
\text { sehat }\end{array}$ & 7 & $\star \star \star \star \star$ \\
\hline 01:03:00.000 & Terlaksananya Trias UKS/M & 5.06 & $\star \star \star \star$ \\
\hline 01:04:00.000 & Penerapan Perilaku Hidup Bersih dan Sehat & 6.34 & $\star \star \star \star$ \\
\hline 01:05:00.000 & $\begin{array}{l}\text { Terlaksananya program UKS/M di sekolah ditangani oleh anak (child to } \\
\text { child program) }\end{array}$ & 6.87 & $\star \star \star \star \star$ \\
\hline 01:06:00.000 & Rencana kegiatan UKS/M & 7 & $\star \star \star \star \star$ \\
\hline 02:00:00.000 & Pelayanan kesehatan & 6.92 & $\star \star \star \star \star$ \\
\hline 02:01:00.000 & Terlaksananya Trias UKS/M & 6.93 & $\star \star \star \star \star$ \\
\hline 02:02:00.000 & Peran dan keterlibatan Puskesmas & 6.9 & $\star \star \star \star \star$ \\
\hline 03:00:00.000 & Pembinaan lingkungan sekolah sehat & 6.51 & $\star \star \star \star$ \\
\hline 03:01:00.000 & $\begin{array}{l}\text { Meningkatnya pengetahuan sikap dan perilaku peserta didik tentang hidup } \\
\text { sehat }\end{array}$ & 7 & $\star \star \star \star \star$ \\
\hline 03:02:00.000 & Penerapan Perilaku Hidup Bersih dan Sehat & 5.89 & $\star \star \star \star \star ~$ \\
\hline 03:03:00.000 & Bebas jentik nyamuk & 6.8 & $\star \star \star \star \star$ \\
\hline 03:04:00.000 & Penerapan Perilaku Hidup Bersih dan Sehat & 5.72 & $\star \star \star \star ~$ \\
\hline 03:05:00.000 & Ventilasi dan pencahayaan kelas yang memadai & 7 & $\star \star \star \star \star$ \\
\hline 03:06:00.000 & Memiliki kamar mandi/WC yang cukup jumlahnya & 7 & $\star \star \star \star \star$ \\
\hline 03:07:00.000 & Ketersediaan air bersih & 7 & $\star \star \star \star \star$ \\
\hline 03:08:00.000 & Ketersediaan sabun di kamar mandi dan di tempat cuci tangan & 7 & $\star \star \star \star \star$ \\
\hline 03:09:00.000 & Ketersediaan sarana dan prasarana UKS/M; & 7 & $\star \star \star \star \star$ \\
\hline 03:10:00.000 & Ketersediaan kantin sehat & 7 & $\star \star \star \star \star$ \\
\hline 03:11:00.000 & Bebas jentik nyamuk & 7 & $\star \star \star \star \star$ \\
\hline 03:12:00.000 & Menerapkan kawasan tanpa rokok & 7 & $\star \star \star \star \star$ \\
\hline 03:13:00.000 & Penerapan Perilaku Hidup Bersih dan Sehat & 7 & $\star \star \star \star \star$ \\
\hline 03:14:00.000 & Ketersediaan sarana dan prasarana UKS/M & 7 & $\star \star \star \star \star$ \\
\hline 03:15:00.000 & Memiliki lapangan/aula untuk pendidikan jasmani & 7 & $\star \star \star \star \star$ \\
\hline
\end{tabular}

Sumber: Data Raport Mutu Dirjen Dikdasmen Kemendikbud Tahun 2018 (diadaptasi oleh penulis)

Tabel 3 memberikan gambaran tentang capaian Raport Mutu UKS di SMK PGRI 1 pada tahun 2018. Berdasarkan tabel 3 tersebut, dapat dijelaskan bahwa terdapat tiga aspek yang menjadi penilaian utama dalam raport mutu Usaha Kesehatan Sekolah (UKS). Aspek-aspek penilaian raport mutu Usaha Kesehatan Sekolah (UKS) tersebut mencakup sebagai berikut 1). Pendidikan kesehatan; 2). Pelayanan kesehatan; 3). Pembinaan lingkungan sekolah sehat. Berdasarkan tabel diatas dijelskan bahwa pada aspek pertama tentang pendidikan kesehatan, memperoleh capaian nilai 6.36 dengan kategori UKS 4 . Capain nilai tersebut menunjukkan bahwa raport mutu UKS memiliki kategori yang baik, lebih lanjut tentang baiknya indikator pendidikan kesehatan juga didukung pada sub indikator mengenai meningkatnya perilaku hidup bersih dan sehat dengan nilai sebesar 7 dan meningkatnya pengetahuan sikap dan perilaku peserta didik tentang hidup sehat dengan nilai 7. Data diatas, memberikan sebuah 
gambaran bahwa peningkatan mutu kesehatan yang di dasari dengan pola perilaku hidup sehat menjadi sebuah daya ukur yang positif terhadap peningkatan mutu pendidikan di SMK PGRI 1 Salatiga.

Namun demikian bahwa data dari hasil raport mutu tersebut, masih kurang sesuai dengan kondisi nyata sekolah yang ada. Capaian hasil raport mutu yang diperoleh SMK PGRI 1 Salatiga, merupakan hasil dari pengisian Evaluasi Diri Sekolah (EDS) yang merupakan dasar utama munculnya raport mutu sekolah. Evaluasi Diri Sekolah (EDS) merupakan data dan informasi yang berasal dari sekolah sehingga dapat menggambarkan kondisi sekolah. Hasil penelitian Nanang dan Rusman (2019:25) mengatakan bahwa Evaluasi Diri Sekolah (EDS) berupaya untuk menyampaikan hasil evaluasi kondisi sekolah dalam bentuk data dan informasi sesuai dengan instrumen pemetaan mutu yang dikembangkan oleh Direktorat Jenderal Pendidikan Dasar dan Menengah dengan ketentuan yang ada.

Sebagai sebuah sekolah yang memiliki Program Keahlian Kesehatan, seyogyanya seluruh warga sekolah mampu untuk mewujudkan perilaku hidup bersih dan sehat. Kondisi nyata sekolah menggambarkan bahwa secara umum perilaku hidup bersih dan sehat masih belum dapat diterapkan sepenuhnya disekolah khususnya didalam kegiatan pembelajaran. Hal tersebut disampaikan oleh Wakil Kepala sekolah Bidang Sarana dan Prasarana bahwa "perilaku hidup bersih dan sehat masih belum dilakukan baik guru dan peserta didik di SMK PGRI 1 Salatiga". Berdasarkan keterangan tersebut, nampaknya relevansi antara hasil capaian raport mutu tentang Usaha Kesehatan Sekolah (UKS) dengan kondisi riel di sekolah masih belum sesuai dengan harapan, akan tetapi berbagai upaya terus dilakukan oleh SMK PGRI 1 Salatiga guna mendukung Usaha Kesehatan Sekolah, salah satunya dengan diadakannya kegiatan ekstrakurikuler Kader Kesehatan Remaja (KKR) dan Palang Merah Remaja (PMR) sebagai bagian dari program kegiatan kesiswaan.

Sub indikator yang kedua dalam raport mutu Usaha Kesehatan Sekolah (UKS) pada indikator pelayanan kesehatan adalah peran dan keterlibatan Puskesmas dengan nilai 6.9 kategori UKS 4. Keterlibatan Pusat Kesehatan Masyarakat (Puskesmas) dalam peningkatan mutu sekolah khususnya Usaha Kesehatan Sekolah (UKS) di SMK PGRI 1 Salatiga salah satunya diwujudkan melalui kegiatankegiatan sosialisasi kesehatan yang dilakukan oleh pihak Puskesmas kepada sekolah, selain dengan menjalin kerja sama atau MoU antara pihak sekolah dengan Puskesmas dalam rangka Program Praktek Kerja Lapangan. Implementasi dalam penerapan usaha kesehatan sekolah tidak terlepas dari dukungan berbagai sektor baik pemerintah maupun masyarakat. Hal tersebut senada disampaikan Ervina (2018: 18) perlunya dukungan dari berbagai sektor untuk mewujudkan sosialisasi Usaha Kesehatan Sekolah (UKS).

Sedangkan sub indikator yang ketiga adalah pembinaan lingkungan sekolah sehat, pada sub indikator ini nilai raport mutu yang dihasilkan sebesar 6,51 dengan kategori UKS 4. Dari uraian sub indikator yang ketiga, dapat dipahami bahwa pembinaan terhadap lingkungan sekolah sehat di SMK PGRI 1 Salatiga, secara umum menjadi bagian dari prioritas program sekolah. Hal tersebut menunjukkan bahwa upaya sekolah untuk terus mengembangan perilaku hidup sehat terus dilakukan baik melalui kegiatan sosialisasi maupun kegiatan-kegiatan kesiswaan. Upaya untuk peningkatan mutu baik pendidikan dan kesehatan di SMK terus perlu dilakukan, dengan melalui berbagai macam rencana strategi. Rencana strategi peningkatan mutu pendidikan dan kesehatan sekolah perlu dikembangkan dan diimplementasikan di sekolah berdasarkan kebutuhan yang ada (Herliana, 2018: 81). Lebih lanjut lagi bahwa peningkatan tersebut tidak hanya sekedar pada peningkatan mutu pendidikan kesehatan, akademik namun juga berupa peningkatan sikap dan perilaku hidup peserta didik.

Penanaman tentang pengetahuan sikap dan perilaku peserta didik tentang hidup sehat merupakan tujuan utama dalam rangka melakukan pembinaan lingkungan hidup sehat. Oleh karena itu, sebagai sekolah yang memiliki Program Keahlian Tata Busana, Keperawatan dan Teknologi Laboratorium Medik, SMK PGRI 1 Salatiga terus berupaya untuk melakukan penanaman dan sosialisasi tentang perilaku hidup sehat. Penanaman dan sosialiasi hidup sehat seyogyanya perlu dikoordinasikan oleh seluruh warga sekolah agar dapat terwujud dan berjalan dengan baik. Dalam mewujudkan perilaku hidup sehat sekolah tidak hanya sekedar sosialisasi, namun wujud nyata secara implementatif juga perlu dilakukan (Yoyok, 2014: 110).

Implementasi tentang sistem penjaminan mutu sekolah akan mendorong peningkatan mutu pendidikan. Munculnya perilaku-perilaku hidup yang sehat, salah satunya menjadi bagian dalam indikator tersebut. Untuk menjamin keberlangsungan hidup sehat maka perlu mendapatkan dukungan dari seluruh warga sekolah (Laporan Pengembangan Sekolah Model SPMI, 2018: 15). Perilaku menuju hidup sehat seyogyanya tidak bisa terlepas dari peran serta seluruh warga sekolah, hal tersebut juga 
perlu ditunjang dari segi sarana dan prasarana serta sumber daya manusia yang memadahi. Dengan adanya lingkungan sekolah yang bersih, sehat dan kondusif, maka akan menghasilkan proses pembelajaran yang baik. Dalam point indikator pembinaan lingkungan sehat terdapat beberapa faktor penting yang mendukung pembinaan lingkungan hidup sehat di SMK PGRI 1 Salatiga. Nampaknya, faktor-faktor tersebut tidak dapat terlepas dari dua hal penting yakni: 1) Kesadaran dari seluruh warga sekolah untuk mewujudkan sebuah perilaku hidup sehat; 2) Sarana dan prasarana sebagai penunjang dalam mewujudkan perilaku hidup sehat di SMK PGRI 1 Salatiga.

\section{SIMPULAN DAN SARAN}

Pelaksanaan Usaha Kesehatan Sekolah (UKS) di SMK PGRI 1 Salatiga dilaksanakan melalui berbagai wujud kegiatan yang dilakukan oleh guru dan peserta didik diantaranya adalah PMR dan KKR. Berdasarkan hasil penilaian raport mutu sekolah khususnya pada raport mutu Usaha Kesehatan Sekolah (UKS) memperoleh capaian sebesar 6.6 dengan kategori UKS 4. Berdasarkan pada hasil analisis hasil raport mutu tersebut menunjukkan bahwa capaian raport mutu SMK PGRI 1 Salatiga termasuk dalam kategori symbol bintang empat. Wujud ketercapain hasil raport mutu pada Usaha Kesehatan Sekolah (UKS) tidak dapat terlepas dari dua hal penting yakni 1). Kesadaran dari seluruh warga sekolah untuk mewujudkan sebuah perilaku hidup sehat; 2). Sarana dan prasarana sebagai penunjang dalam mewujudkan perilaku hidup sehat di SMK PGRI 1 Salatiga.

Merujuk pada simpulan penelitian diatas, SMK PGRI 1 Salatiga sebagai satuan pendidikan yang berorientasi pada pendidikan menengah kejuruan, perlu melakukan peningkatan kaitanya dengan fasilitas penunjang sekolah serta melakukan sosialisasi yang lebih intensif terkait dengan penyelenggaraan Usaha Kegiatan Sekolah yang dapat dilakukan melalui kegiatan PMR atau Program Keahlian Keperawatan.

\section{DAFTAR PUSTAKA}

Arianti, Urgensi Lingkungan Belajar yang Kondusif dalam Mendorong Siswa Belajar Aktif. Jurnal Kependidikan Didaktika, Vol. 11, No. 1, Juni 2017. Jurusan Tarbiyah STAIN Watampone

D. Fitri, W. Ismanto. ISO 9000 Quality Management System in Improving Product Quality and Service and Customer Satisfaction In the International Market. Jurnal Dimensi, Vol 7, No. 3, 421-433, November 2018, ISSN: 2085-9996

Direktorat Jenderal Pendidikan Dasar dan Menengah Kementerian Pendidikan dan Kebudayaan Republik Indonesia. 2019. Perangkat Instrumen Pemetaan Mutu Pendidikan Dasar dan Menengah Tingkat Sekolah Menengah Kejuruan. Jakarta: Kementerian Pendidikan dan Kebudayaan Republik Indonesia.

Effendy, Nasrul 2008. Dasar-Dasar Keperawatan Kesehatan Masyarakat. Jakarta: EGC

Elvina, Teuku Tahlil, Mulyadi. Pelaksanaan Program Usaha Kesehatan Sekolah (UKS) di Puskesmas. Jurnal Ilmu Keperawatan, Vol. 6, No. 2, 2018, Fakultas Keperawatan, Universitas Syiah Kuala.

Herliana. Analisis Peta Mutu Pendidikan pada Jenjang Sekolah Menengah Kejuruan (SMK) di Provinsi Aceh. Jurnal Serambi Ilmu, Vol. 19, Nomor 1, Edisi Maret 2018. Universitas Serambi Mekah.

Instruksi Presiden Nomor 9 Tahun 2019 Tentang Revitalisasi Sekolah Menengah Kejuruan

LPMP Jawa Tengah. 2018. Laporan Pengembangan Sekolah Model Sistem Penjaminan Mutu Internal SMK PGRI 1 Salatiga. Semarang: LPMP Jawa Tengah.

Nanang dan Rusman. Analisis Kebutuhan Pelatihan Standar Penilaian Berbasis Data Pemetaan Mutu Pendidikan PMP) pada Jenjang Sekolah Dasar (SD) di Kota Makasar. Jurnal Penelitian Ilmu Pendidikan, Volume 12, Nomor 1, 2019. UNY.

Oemar Hambalik. 2013.Kurikulum dan Pembelajaran. Jakarta: PT Bumi Aksara.

Peraturan Menteri Pendidikan dan Kebudayaan Republik Indonesia Nomor 20 Tahun 2016 Tentang Standar Kompetensi Lulusan. 
Peraturan Menteri Pendidikan Nasional No 24 Tahun 2007 Tentang Standar Sarana dan Prasarana SMA/MA.

Peraturan Pemerintah Nomor 13 Tahun 2015 Tentang Standar Nasional Pendidikan.

Raport Mutu Dirjen Dikdasmen Kemendikbud Tahun 2018.

Sallis Edward. 2008. Total Quality Management In Education. Manajemen Mutu Pendidikan, Yogyakarta: IRCiSoD.

Sallis Edward. 2012. Total Quality Management In Education. Manajemen Mutu Pendidikan, Yogyakarta: IRCiSoD.

Saril. Total Quality Management (TQM) Sebagai Wujud Peningkatan Mutu Pendidikan. Jurnal Manajemen Pendidikan Islam, Volume. 9, No. 2 Agustus 2019, P-ISSN: 2407-8107 E-ISSN: $2685-4538$

Sugiyono. 2011. Metode Penelitian Kuantitatif, Kualitatif dan R\&D. Bandung: Alfabeta.

Sugiyono. 2013. Metode Penelitian Kombinasi (Mixed Methods). Bandung: Alfabeta.

T. Supriyanto, Implementasi Total Quality Management Dalam Sistem Manajemen Mutu Pembelajaran di Institusi Pendidikan. Jurnal Cakrawala Pendidikan, Februari 2011, Th. XXX No. 1.

Togatorop, M. (2017) Pengaruh Biaya Pendidikan Terhadap Mutu Sekolah Sma Swasta. SCHOLARIA: jurnal Pendidikan dan Kebudayaan, Vol. 7, No. 3, 2017.

Usman, Husaini. 2013. Manajemen: Teori, Praktek dan Riset Pendidikan. Jakarta: PT Bumi Aksara.

Y.B. Prasetyo, A.M. Hudha, W.T. Mayangsari. Implementation Health School Program to Improve Health Status for School Age at East Lombok. Jurnal Kedokteran YARSI 22 (2) : 102-113 (2014). UMM.

Zahroh A. (2015). Total Quality Management: Capaian Kualitas Output Melalui Sistem Kontrol Mutu Sekolah. Jurnal CENDEKIA, Vol. 9, No. 1, April 2015. 